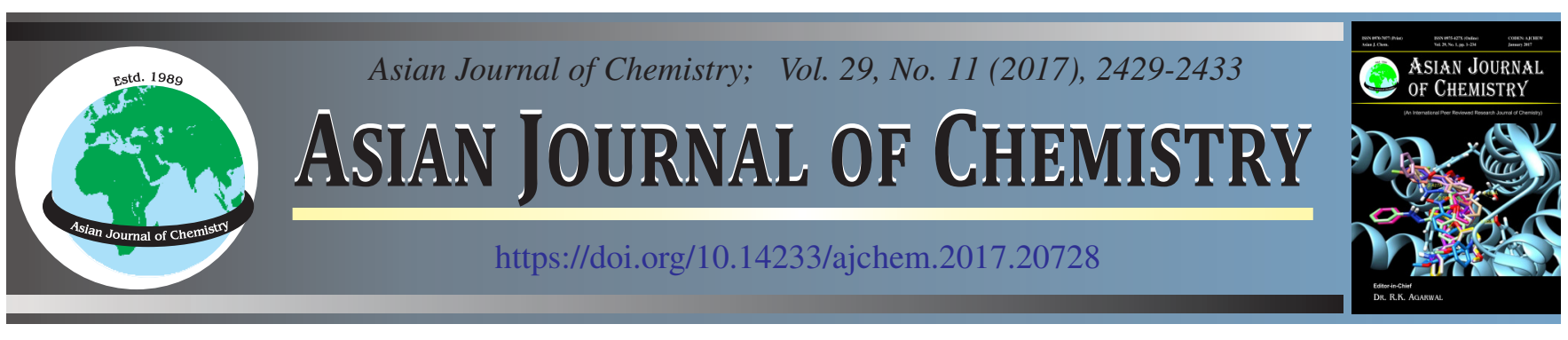

\title{
Evaluation Performance of Molecularly Imprinted Polymer Prepared by Two Different Polymerization Method for Atenolol Recognition in Human Plasma
}

\author{
Aliya Nur Hasanah ${ }^{1, *}$, Shendi Suryana ${ }^{1,2}$, Mutakin $^{1}$ and Driyanti Rahayu ${ }^{1}$
}

${ }^{1}$ Pharmaceutical Analysis and Medicinal Chemistry Department, Faculty of Pharmacy, Universitas Padjdjaran, Jl Raya Bandung Sumedang KM 21.5, 45363, Jatinangor, Sumedang, Indonesia

${ }^{2}$ Pharmacy Department, Faculty of Mathematics and Natural Sciences, Universitas Garut, Jl. Jati No. 42B 44151, Tarogong, Garut, Indonesia

*Corresponding author: E-mail: aliya.n.hasanah@unpad.ac.id; aliya_nh@yahoo.com

\begin{abstract}
Two molecularly imprinted polymers (MIPs) were prepared via bulk polymerizations and precipitation polymerization with methacrylic acid as functional monomer, atenolol as the template, ethylene glycol di-methacrylate as a crosslinker. Molecularly imprinted polymer prepared via precipitation polymerization gives the best character as sorbent by a higher number of binding site and higher association constant compared to bulk. Plasma sample which was spiked with atenolol gives recovery more than $96 \%$ after pretreatment with selected polymer. Selectivity test showed that MIP made by precipitation polymerization could be used for selective recognition of atenolol from plasma samples spiked with other drugs. This developed molecularly imprinted polymer-solid phase extraction (MIP-SPE) could be further used as extraction method in antihypertension drug analysis from biological samples.
\end{abstract}

Keywords: Molecularly imprinted polymer, Atenolol, molecular recognition, Solid phase extraction.

ᄂ - - - - - - - _ - - - - - - - - - - - - - - - - - - - - -

\section{INTRODUCTION}

Atenolol is a synthetic, $\beta$-selective (cardioselective), adrenoreceptor blocking agent [1]. It is chemically described as benzene acetamide. 4-[2'-Hydroxy-3'-[(methyl ethyl)amino]propoxy]benzene acetamide [2]. $\beta$-Blocker have long been considered to be well documented first-line drugs in the treatment of hypertension [3]. They help the heart work more efficiently, thereby reducing blood pressure, heart rate, muscle tremors and even anxiety. Their use has been prohibited in-competition and outof-competition for several sports, especially in activities that require vehicle control and bodily movement as these compound can induce a reduction in heart rate and tremors as well as improve general performance during competition, they have been considered to be unsportsman like performance enhancers, as they give individual athletes an unfair advantage over others [4]. Atenolol can cause serious adverse effects, including jaundice, dark urine and stomach pain. An overdose of $\beta$-blockers may lead to life-threatening situation [5]. The concentration of atenolol was small in biological matrices. As a drug that was used for long-term treatment, drug monitoring was needed for atenolol [6]. The most complicated analyses involve complex matrices such as those encountered in the analysis of the biological and environmental sample. It is accepted that the most important step in such analytical methods is sample preparation [6].

Solid-phase extraction (SPE) constitutes a powerful method for the extraction and the purification of compounds contained in complex matrices $[7,8]$. Various formats of solidphase extraction is currently a routine sample preparation technique employed in numerous environmental and bioanalytical application $[9,10]$. Separation on most current SPE sorbent is based on physicochemical retention on functionalized surface and the SPE column retains not only the target analytes but also other matrix components [11]. Solid-phase extraction columns based on polymers have been developed to overcome the uncertainty caused by such secondary interaction [9]. One such approach has been the development and evaluation of molecularly imprinted polymers (MIPs) [12]. The use of MIP in the solid phase extraction (SPE) has high benefits because it produces selective extraction of analytes and eliminates sample matrices [13]. Compared with other selective sorbents such as immuno-affinity materials, MIPs demonstrate very good thermal and chemical stability, repeated operations without loss of activity, high mechanical strength, durability to heat and pressure and applicability in harsh chemical media $[14,15]$. The advantages of MIP-SPE over other selective sorbents have made MIP-SPE as one of the most important techniques for 
selective sample concentration in biological, pharmaceutical and environmental fields [16]. MIPs involves the synthesis of cross-linked polymers around a template molecule (the analyte). Once the polymer has been formed the template is removed by washing, leaving an imprint of the analyte template. Ideally, this gives a sorbent on which highly selective, reversible binding of the analyte can achieve [17].

Originally, bulk polymerization was the first strategy used to synthesize imprinted polymers. Using this procedure and after the unavoidable grinding and sieving steps, the obtained particles possessed a various particle size distribution invariably with weak binding site accessibility for the target analite [18]. A great effort has been made during past years in developing new polymerization methodologies to obtain MIP beads with proper physical characteristics (size, porosity, pore volume, surface area). Precipitation polymerization has been proposed as a simple and easy strategy for the formation of MIP beads quickly in excellent yield [19]. Thus, this study evaluates the polymer performance for selective recognition of atenolol which is made using bulk polymerization against precipitation polymerization to show the best polymerization methodologies with particular recognition and then applying it for atenolol recognition in plasma.

\section{EXPERIMENTAL}

Methacrylic acid (MAA), ethylene glycol di-methacrylate (EGDMA), 2,2-azoisobutyronitrile (AIBN) were provided by Sigma-Aldrich. Methanol pro-HPLC, acetonitrile pro-HPLC were purchased from Fischer Scientific. Atenolol was furnished by the Central Pharmaceutical Co., Ltd. Tianjin.

UV-visible spectrophotometer (Specord 200 Analytic Jena), Water bath shaker (Memmert), HPLC (Dionex Ultimate 3000 with UV detector and column Enduro C18G 125A 250 $\times 4.6 \mathrm{~mm}$, Fourier transform infrared (FTIR) Shimadzu prestige21, scanning electron microscope (Hitachi TM 3000), centrifugation (Eppendorf centrifuge 5424R).

UV spectroscopic analysis of the interaction between template molecules and functional monomers: To choose a solvent that showed the best interaction between template molecules and functional, then investigated with UV titration. For UV titration, a stock solution of atenolol was prepared (c $\left.=1 \times 10^{-3} \mathrm{ML}^{-1}\right)$ in methanol and a mixed solvent containing methanol-acetonitrile (1:9). The solution of guest methacrylic acid in order of $1 \mathrm{ML}^{-1}$ was also prepared in methanol and mixed solvent too. A solution of various concentration containing atenolol and increasing concentration of functional monomer were prepared separately. The spectra of this solution were recorded using UV method. Binding constant was calculated according to the Genesis-Hildebrand equation. $\mathrm{K}_{\mathrm{a}}$ was calculated following the equation stated below

$$
1 /\left(\mathrm{A}-\mathrm{A}_{\mathrm{o}}\right)=1 /\left\{\mathrm{K}\left(\mathrm{A}_{\max }-\mathrm{A}_{\mathrm{o}}\right)[\mathrm{MAA}]\right\}+1 /\left[\mathrm{A}_{\max }-\mathrm{A}_{\mathrm{o}}\right]
$$

here $A_{o}$ is the absorbance of the receptor in the absence of a guest; $\mathrm{A}$ is the absorbance recorded in the presence of added guest, $\mathrm{A}_{\max }$ is absorbance in the presence of added [MAA] $\max$ and $\mathrm{K}$ is the association constant $\left(\mathrm{M}^{-1}\right)$. The association constant $(\mathrm{K})$ could be determined from the slope of the straight line of the plot of $1 /\left(\mathrm{A}-\mathrm{A}_{\mathrm{o}}\right)$ against 1/[MAA] [20].
Molecularly imprinted polymer: In this study, the molecularly imprinted polymer was prepared via precipitation polymerization and bulk polymerization, to compared which one that showed best analytical performance.

Bulk polymerization was made as follows: Atenolol as a template $(2 \mathrm{mmol})$, methacrylic acid as functional monomer ( $8 \mathrm{mmol})$, followed by cross-linker EGDMA (40 mmol) and initiator AIBN (0.5 mmol) was dissolved in methanol (4 mL) in a vial tube. The appropriate homogeneous solutions were sonicated for $20 \mathrm{~min}$. Then the mixtures were incubated in the water bath $60{ }^{\circ} \mathrm{C}$ for $18 \mathrm{~h}$. The last bulk rigid polymers were ground in a laboratory mortar pestle and wet-sieved with methanol to get particles below $100 \mu$ m diameter. The particles were extracted to remove the atenolol as a template using Soxhlet apparatus for $24 \mathrm{~h}$ in methanol:acetic acid $(9: 1)$ and dried at $55^{\circ} \mathrm{C}$ for $3 \mathrm{~h}$ and stored at room temperature for further experiments. Quantitative removal of the template was ensured by monitoring the amount of template remaining in the extraction solvent by HPLC. The non-imprinted polymers (NIPs) were prepared in similar ways as used for the corresponding imprinted polymers except without template molecule during polymerization.

Precipitation polymerization was also conducted and the procedures were as follows: $1.3317 \mathrm{~g}(5 \mathrm{mmol})$ atenolol was dissolved in $10 \mathrm{~mL}$ methanol with $1.700 \mathrm{~mL}(20 \mathrm{mmol})$ methacrylic acid and $18.794 \mathrm{~mL}$ (100 mmol) ethylene glycol di-methacrylate. The mixture was sonicated for $5 \mathrm{~min}$ to be dissolved and mixed correctly, then $1.493 \mathrm{~mL}(10 \mathrm{mmol})$ azobisisobutyronitrile was added. The solution was sonicated for another $20 \mathrm{~min}$ to dissolve and mixed entirely. Subsequently, the solution was sealed and immersed at $60^{\circ} \mathrm{C}$ in the thermostat for $24 \mathrm{~h}$ until white lump polymers were formed. The polymers were ground and filtered through $75 \mu \mathrm{m}$ sieve. The particles collected were then placed in Soxhlet extraction, extracted with $\mathrm{CH}_{3} \mathrm{OH} / \mathrm{CH}_{3} \mathrm{CO}_{2} \mathrm{H}(\mathrm{v} / \mathrm{v}, 9 / 1)$ until the atenolol cannot be detected. A UV-visible spectrophotometer monitored the stage. Afterward, the polymers were washed with methanol for washing out the acetic acid. Last, they were dried in an oven at $55^{\circ} \mathrm{C}$ for $24 \mathrm{~h}$, after which the atenolol molecularly imprinted polymers with methacrylic acid as the functional monomer were obtained.

Non-imprinted polymers (NIPs) were prepared by the same procedure in the absence of template molecule.

Batch rebinding and isotherm adsorption studies: The rebinding batch-mode experiments were performed in methanol and methanol-acetonitrile mix. Binding analysis was carried out by incubating $20 \mathrm{mg}$ of polymer in $1,5 \mathrm{~mL}$ volume of the atenolol solution in different concentration (2, 4 and 6 ppm) on a vial for $24 \mathrm{~h}$. HPLC then analyzed the solution. The isotherm adsorption graph was then made with the curve between bound and free atenolol.

Optimization of solid phase extraction (SPE) system: The $200 \mathrm{mg}$ of MIP and NIP particles were dry packed in $3 \mathrm{~mL}$ Chromabond® SPE cartridges using $20 \mathrm{~mm}$ porous PTFE frits. The cartridges then further called MI-SPE and NISPE. Equilibration of the columns, loading and washing was performed using $1 \mathrm{~mL}$ aliquots of the similar solutions and elution of the retained analytes with different elution solvents. 
Full vacuum was applied between each step to dry the stationary phases. The collected fractions were analysis by HPLC and isocratic elution using a mixture of methanol:water + TEA $0.05 \%$ adjust $\mathrm{pH} 3$ with phosphoric acid (85:15) with the flow rate set at $0.8 \mathrm{~mL}$ per min.

Application of MIP for extraction of atenolol from plasma samples: Blood plasma samples were prepared by centrifugation the collected blood $5000 \mathrm{rpm}$ for $5 \mathrm{~min}$ at 14 ${ }^{\circ} \mathrm{C}$ and careful collection of the transparent top layer. The blood plasma samples then were spiked with 2 ppm of atenolol in water. The spiked serum then applied to MISPE and NISPE system. The SPE system was conditioned with methanol, washing with acetonitrile and elute with $3 \times 1 \mathrm{~mL}$ methanol + acetic acid $5 \%$ 9:1. Full vacuum was applied between each step to dry the stationary phase. The elution fraction then analyzed by HPLC and isocratic elution using a mixture of methanol:water + TEA $0.05 \%$ adjust $\mathrm{pH} 3$ with phosphoric acid $(85: 15)$ with the flow rate set at $0,8 \mathrm{~mL}$ per min. The recovery percentage of the elution fraction was then calculated.

\section{RESULTS AND DISCUSSION}

Spectrophotometric analysis of the interaction between atenolol and methacrylic acid: A $0.001 \mathrm{mmol} \mathrm{L}^{-1}$ solution of atenolol in methanol and mixed solvent added with different amounts of methacrylic acid each time to make the molar ratio of template molecule to functional monomer 1:0, 1:5, 1:10, 1:50, 1:100, respectively. The ultraviolet absorption spectra were shown in Fig. 1.

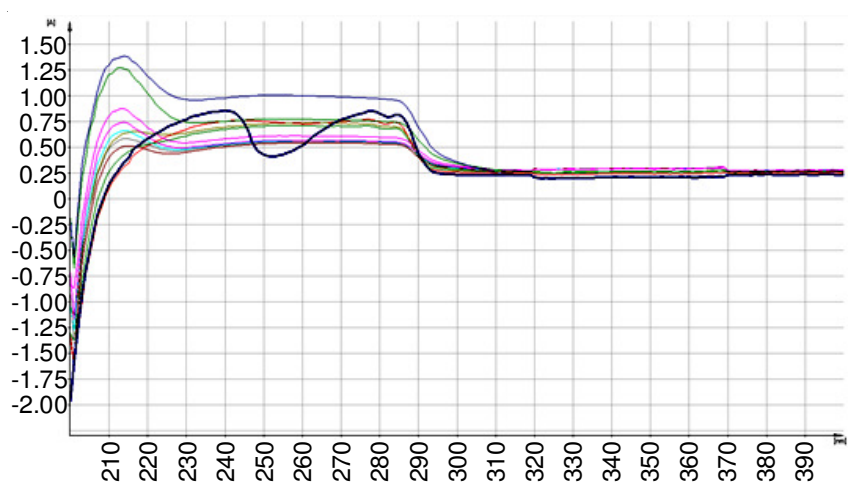

Fig. 1. UV absorption spectrum of atenolol to the different molar ratio of methacrylic acid in methanol

As shown in Fig. 1, when adding methacrylic acid into atenolol in methanol solution, as the concentration of functional monomer increased, the blue shift of spectra was witnessed, which indicated that the template molecule and functional monomer interacted with each other and generated a compound. The widespread use of methacrylic acid (MAA) as the functional monomer is related to the fact that carboxylic acid (the functional group) can act as a hydrogen bond and proton donor, as well as a hydrogen bond acceptor [21].

The association constant $\left(\mathrm{K}_{\mathrm{a}}\right)$ as determined by UV titration method for ATE-MAA in methanol is found to be $5.76 \times 10^{2}$ $\mathrm{M}^{-1}$ higher than a mixed solution that showed $\mathrm{K}_{\mathrm{a}}$ was $3.42 \times$ $10^{2} \mathrm{M}^{-1}$, so for further study, imprinted polymer only prepared in methanol as solvent.
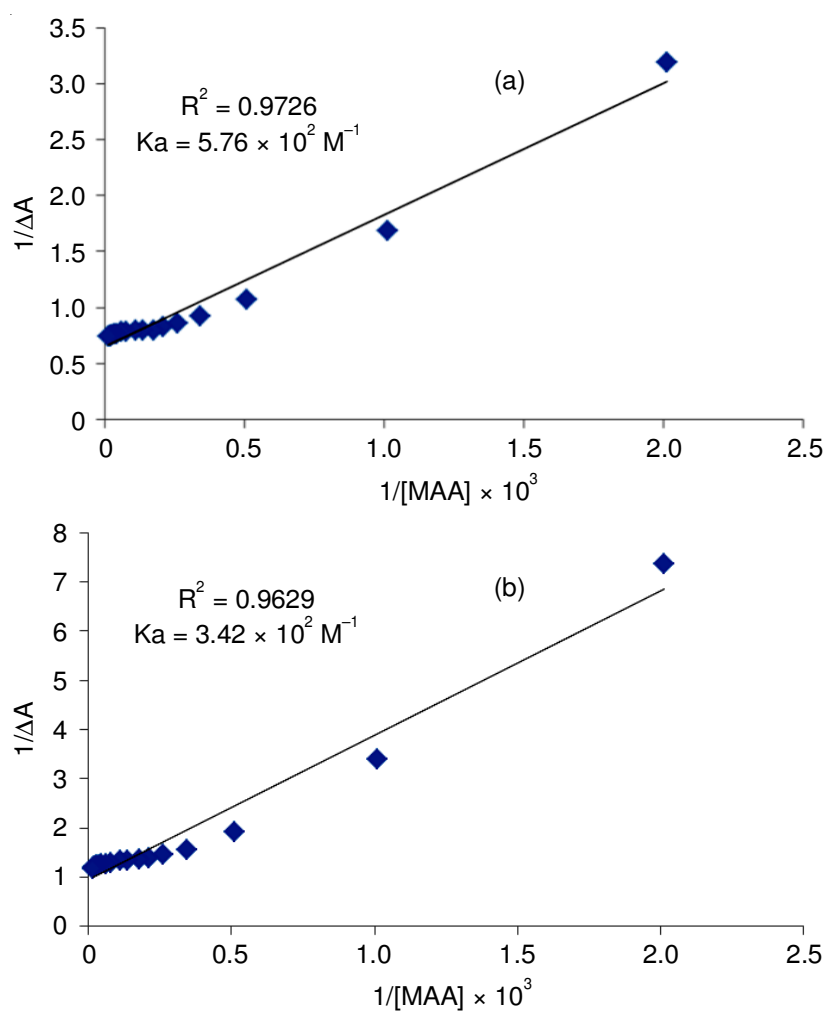

Fig. 2. Association constant curve of ATE-MAA determined by UV method (a) In methanol (b) in mixed solvent

Batch rebinding and isotherm adsorption studies: Fig. 3 showed that the binding of MIP made via bulk polymerization (MIP1) gives $47.39 \%$ and $27.82 \%$ for non-imprinted one in methanol, $27.82 \%$ and $12.83 \%$ for MIP1 and NIP1 in methanol + acetonitrile (1:9), respectively. While precipitation polymerization (MIP2) gives $69.15 \%$ and $43.21 \%$ for nonimprinted one in methanol and $59.12 \%$ and $44.13 \%$ for MIP2 and NIP2 in methanol:acetonitrile (1:9), respectively.

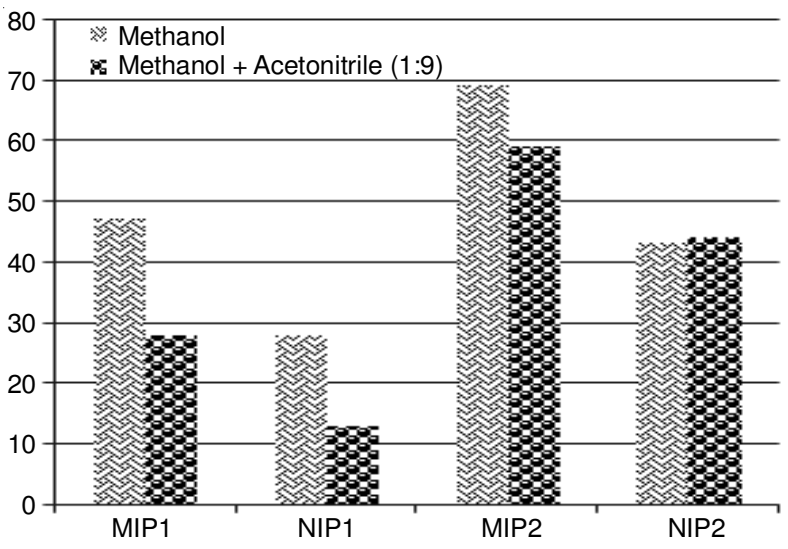

Fig. 3. Binding ability in various solvent

To find out a number of binding sites, adsorption isotherm was made and then fitted to Freundlich. The results of it were showed at Table-1.

Optimization of condition on SPE: To find out the best condition for conditioning, loading, washing and elution, a series of solvent were used and the recovery percentage was measured. 
TABLE-1

FREUNDLICH FITTING PARAMETERS FOR MIP AND NIP

\begin{tabular}{ccccc}
\hline Polymer & $\log \mathrm{K}$ & $1 / \mathrm{n}$ & $\mathrm{K}$ & $\mathrm{n}$ \\
\hline MIP1 & -1.2914 & 1.4328 & 0.051121 & 0.6979341 \\
NIP1 & -2.6394 & 3.4373 & 0.002294 & 0.2909260 \\
MIP2 & -0.7860 & 1.5411 & 0.163682 & 0.6488872 \\
NIP2 & -1.3716 & 1.4037 & 0.042501 & 0.7124029 \\
\hline
\end{tabular}

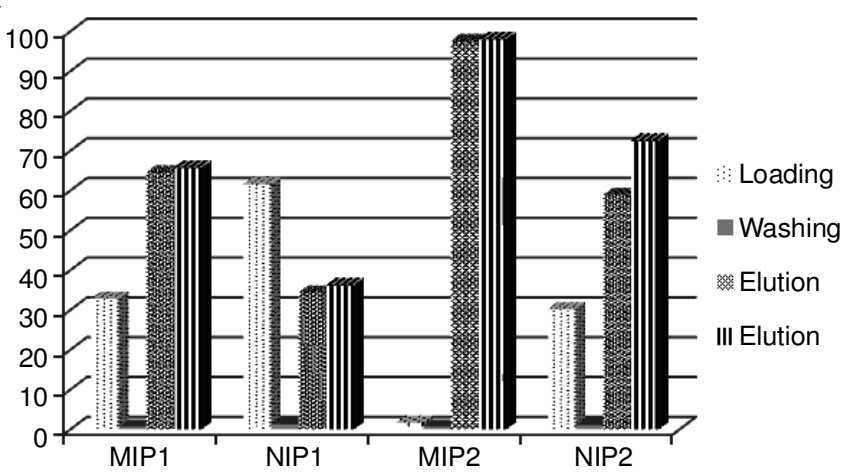

Fig. 4. Optimization of condition on SPE

Application of MISPE on plasma samples: Plasma sample which was spiked with 2 ppm atenolol gives recovery $34.17 \%$ and $7.17 \%$ for MIP1 and NIP1, respectively. Then 96.68 and $55.41 \%$ for MIP2 and NIP2, respectively. This results showed that MIP2 that was prepared by precipitation technique has better binding compared to bulk.

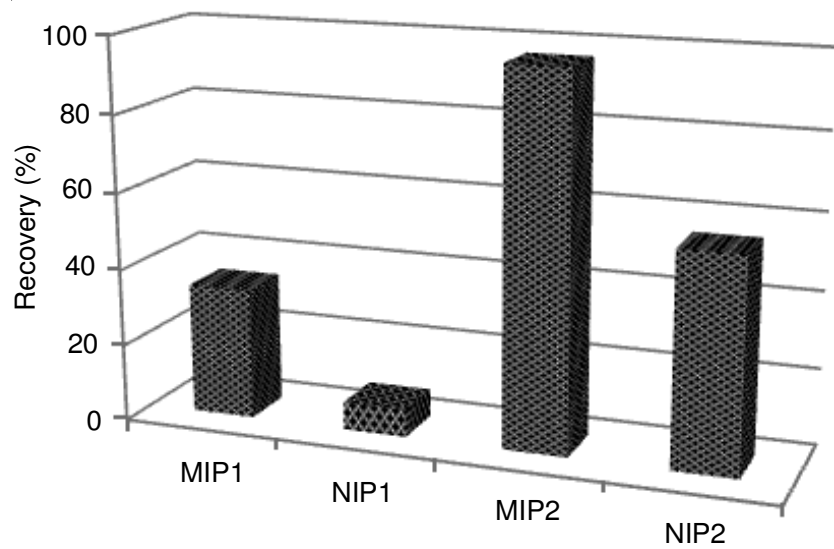

Fig. 5. Recovery percentage of atenolol on spiked plasma

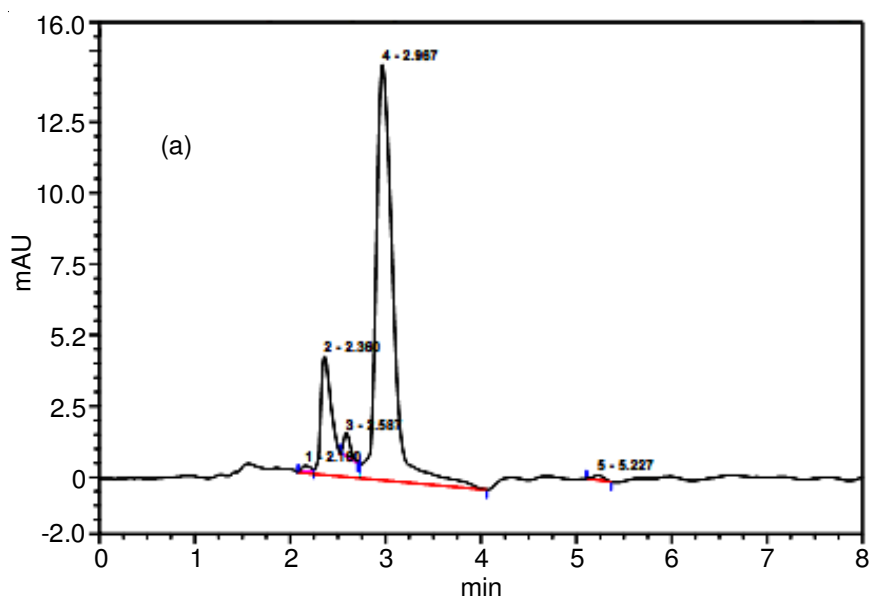

SPE separation of mixture compound in plasma: In order to find out the selectivity of MIP in SPE system (MISPE), some drugs were selected. The drugs being selected was based on possible existence in blood that could interfere atenolol assay. These studies were compared the recoveries percentage of atenolol, caffeine and acetosal through MIP2 and NIP2. The recoveries percentage of each compound using MIP2 cartridges were $92.20 \pm 1.36,35.99 \pm 1.24$ and 0.00 for atenolol, caffeine and acetosal respectively. Caffeine has a relatively higher recovery because it has - $\mathrm{NH}$ in xanthine rings that interacted with $-\mathrm{OH}$ functional group from methacrylic acid to form hydrogen bonding [22].

From chromatogram of spiked blood plasma before and after SPE process (Fig. 8), indicate that MIP process produced a better peak of atenolol. The height of atenolol is higher (with retention time $5.1 \mathrm{~min}$ ) and gives good recoveries percentage fitted with criteria of recovery for biological matrices which is more than $80 \%$ [23].

In infrared spectra (Fig. 7a-b), there is frequency shifting in $\mathrm{C}=\mathrm{O}$ and $-\mathrm{OH}$ which indicates hydrogen bonding between the template and monomer. Because of the hydrogen bonding between template and methyl methacrylate, there is reduction density in $\mathrm{OH}$ and $\mathrm{C}=\mathrm{O}$, which cause a reduction in vibrational frequency before template extraction [13].

\section{Conclusion}

Atenolol molecularly imprinted solid phase extraction made from methacrylic acid as monomer via precipitation polymerization can be used for selective removal of atenolol from the plasma sample. This results was noteworthy for therapeutic drug monitoring of atenolol in hypertension patient and to detect substance abuse in sports

\section{ACKNOWLEDGEMENTS}

This work was supported by Penelitian Unggulan Perguruan Tinggi 2017 Grant from Ministry of Research, Technology and the Higher Education, Republic of Indonesia.

\section{REFERENCES}

1. P.C. Damiani, Talanta, 85, 1526 (2011); https://doi.org/10.1016/j.talanta.2011.06.043.

2. M.S. Vijay, Asian J. Res. Chem, 3, 477 (2010).

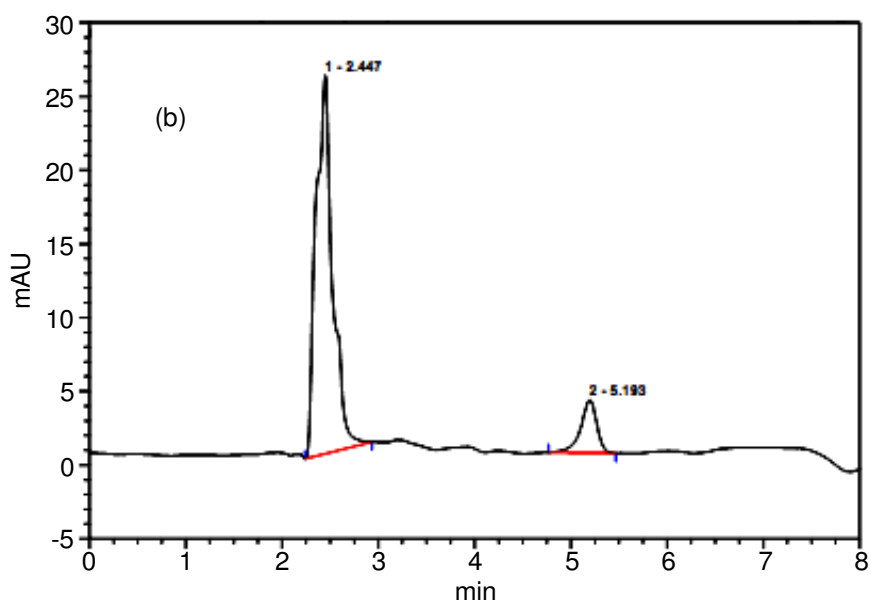

Fig. 6. Chromatogram of (a) blood spike with atenolol without MIP2 pretreatment and (b) blood spike with atenolol after MIP2 treatment 

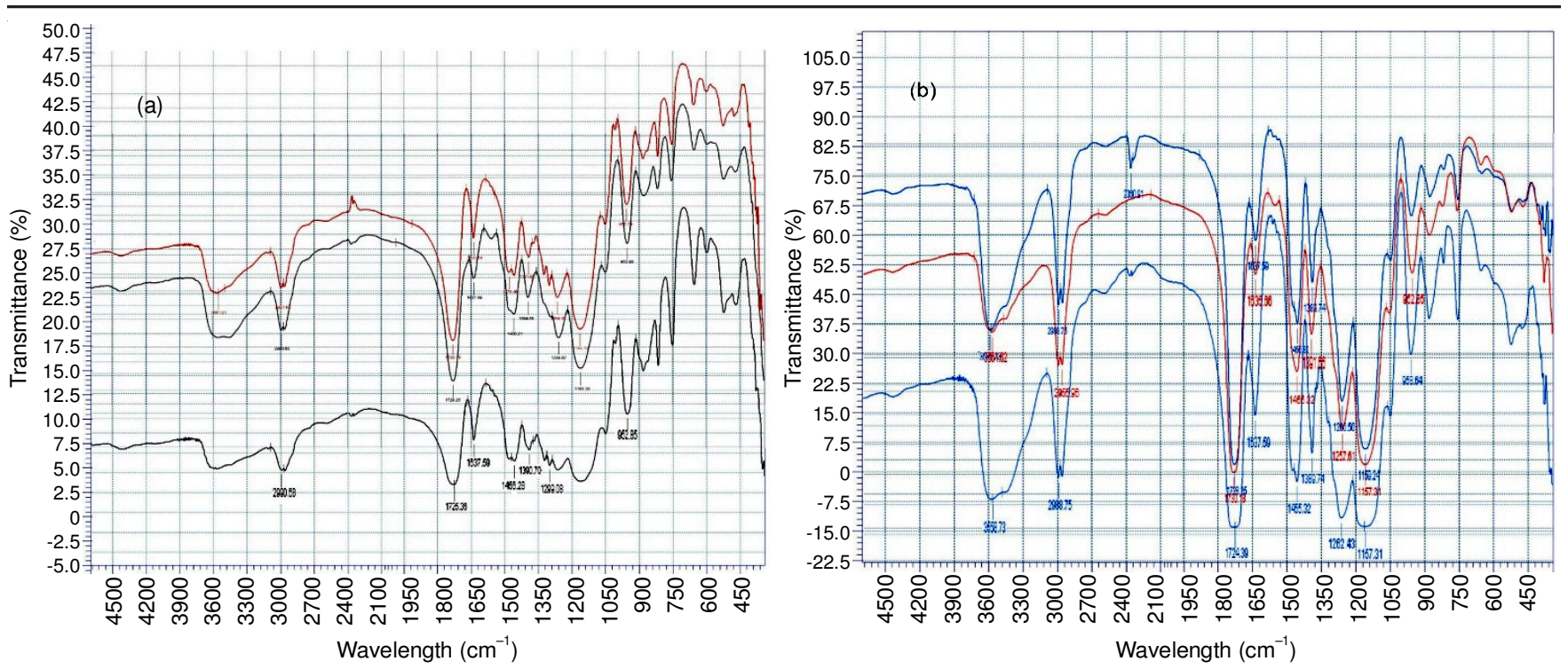

Fig. 7. FTIR spectra of (a) MIP1 (bulk polymerization) (b) MIP2 (precipi-tation polymerization)

3. B. Carlberg, O. Samuelsson and P.L.H. Lindholm, Lancet, 364, 1684 (2004); https://doi.org/10.1016/S0140-6736(04)17355-8.

4. K. Goryñski, A. Kiedrowicz and B. Bojko, J. Pharm. Biomed. Anal., 127, 147 (2016);

https://doi.org/10.1016/j.jpba.2016.03.001.

5. S. Magiera, A. Kolanowska and J. Baranowski, J. Chromatogr. B Analyt. Technol. Biomed. Life Sci., 1022, 93 (2016); https://doi.org/10.1016/j.jchromb.2016.04.010.

6. D. Stevenson, Trends Analyt. Chem., 18, 154 (1999); https://doi.org/10.1016/S0165-9936(98)00094-6.

7. D.A. Wells, Reference Module in Chemistry, Molecular Sciences and Chemical Engineering (2013); https://doi.org/10.1016/B978-0-12-409547-2.04661-8.

8. A. Lagha, N. Adhoum and L. Monser, Chem. Biomed. Methods, 4, 7 (2011);

https://doi.org/10.2174/1875038901004010007.

9. N. Fontanals, R.M. Marce and F. Borrull, J. Chromatogr. A, 1152, 14 (2007); https://doi.org/10.1016/j.chroma.2006.11.077.

10. M.C. Hennion, J. Chromatogr. A, 856, 3 (1999); https://doi.org/10.1016/S0021-9673(99)00832-8.

11. V. Seechamnanturakit and R. Suedee, Int. J. Appl. Sci. Technol., 2, 81 (2012).

12. F.G. Tamayo, E. Turiel and A. Martín-Esteban, J. Chromatogr. A, 1152, 32 (2007); https://doi.org/10.1016/j.chroma.2006.08.095.

13. A.N. Hasanah, R.E. Kartasasmi and S. Ibrahim, J. Appl. Sci. (Faisalabad), 15, 1288 (2015);

https://doi.org/10.3923/jas.2015.1288.1296.
14. F. Qiao, H. Sun, H. Yan and K.H. Row, Chromatographia, 64, 625 (2006); https://doi.org/10.1365/s10337-006-0097-2.

15. G.R. Vasapollo, R.D. Sole, L. Mergola, M.R. Lazzoi, A. Scardino, S. Scorrano and G. Mele, Int. J. Mol. Sci., 12, 5908 (2011); https://doi.org/10.3390/ijms12095908.

16. H. Yan and K.H. Row, Int. J. Mol. Sci., 7, 155 (2006); https://doi.org/10.3390/i7050155.

17. A. Martín-Esteban, Trends Analyt. Chem., 45, 169 (2013); https://doi.org/10.1016/j.trac.2012.09.023.

18. H. Li, F. Lei, P. Li, W. Duan, J. Zhou and X. Tan, Asian J. Chem., 25, 7421 (2013); https://doi.org/10.14233/ajchem.2013.14759.

19. M.C. Cela-Pérez, A. Lasagabáster-Latorre, M.J. Abad-López, J.M. López-Vilariño and M.V. Gónzalez-Rodríguez, Vib. Spectrosc., 65, 74 (2013); https://doi.org/10.1016/j.vibspec.2012.12.002.

20. O. Exner, Chemom. Intell. Lab. Syst., 39, 85 (1997); https://doi.org/10.1016/S0169-7439(97)00057-9.

21. M.H. Abraham, P.P. Duce, D.V. Prior, D.G. Barratt, J.J. Morris and P.J. Taylor, J. Chem. Soc. Perkin Trans., 1355 (1989); https://doi.org/10.1039/p29890001355.

22. F. Qiao and H. Yan, J. Chromatogr. B Analyt. Technol. Biomed. Life Sci., 879, 3551 (2011); https://doi.org/10.1016/j.jchromb.2011.09.040.

23. Food and Drug Administration, U.S. Dep. Heal. Hum. Serv. 410 (2001). http://www.labcompliance.de/documents/FDA/FDA-Others/ Laboratory/f-507-bioanalytical-4252fnl.pdf 